\title{
Zastosowanie transformaty falkowej do analizy sygnałów napięcia spawania
}

\author{
Application of wavelet transform to analysis \\ of welding voltage signals
}

\section{Streszczenie}

W artykule zaprezentowano wyniki badań nad zastosowaniem transformaty falkowej do przetwarzania i analizy sygnałów napięcia spawania. Przeprowadzone badania potwierdzają zalety analizy falkowej i wskazują duży potencjał w detekcji wybranych niestabilności procesu spawania.

Słowa kluczowe: MAG; monitorowanie spawania; analiza sygnałów; transformata falkowa

\begin{abstract}
The article presents the results of research on application of wavelet transform to signal analysis and processing of welding voltage. Studies confirm the benefits of wavelet analysis and shows a lot of potential in the detection of the selected welding process instability.
\end{abstract}

Keywords: GMA; welding monitoring; signal analysis; wavelet transform

\section{Wstęp}

Podczas seryjnej produkcji różnorodnych elementów mechanicznych, w których stosowane są połączenia nierozłączne wykonywane technologią spawania, wykorzystuje się różnorodne metody zapewnienia jakości połączeń spawanych. Jednym ze skutecznych, sposobów kontroli jakości złączy spawanych jest ciągły monitoring i ocena procesu spawania, którego przebieg bezpośrednio przekłada się na jakość uzyskiwanego połączenia. Informacje o stanie procesu spawania zakodowane są w sygnałach opisujących przebiegi parametrów procesowych, takich jak natężenie prądu, napięcie łuku, natężenie przepływu gazu, prędkość podawania drutu, sygnałach resztkowych (dźwięk, drgania, temperatura), promieniowaniu elektromagnetycznym itp. [3]. Niewątpliwą zaletą wykorzystania sygnałów procesowych do monitorowania procesu spawania w trybie "on-line" jest możliwość bieżącej identyfikacji i klasyfikacji niezgodności spawalniczych, co pozwala na szybkie korygowanie wartości wybranych parametrów technologicznych lub naprawę wskazanego odcinka połączenia spawanego.

Skuteczna detekcja i identyfikacja niezgodności procesu spawania wymaga odpowiedniego przetwarzania i analizy sygnałów procesowych. Opracowano szereg różnorodnych metod pozwalających oceniać sygnały procesowe [2]. Wykorzystują one parametry statystyczne, różnorodne przekształcenia przestrzeni wartości sygnałów (np. Transformata Fouriera, Analiza składowych głównych PCA) itp. Należy jednak zauważyć, że analiza sygnałów spawania nie jest zadaniem prostym ze względu na ich dynamiczny i niestacjonarny charakter oraz duży udział składowych losowych. Przykładem sygnału spawania o złożonej strukturze przebiegu wartości amplitud jest sygnał napięcia.
W artykule przedstawiono wyniki badań nad zastosowaniem przekształcenia falkowego do analizy sygnałów napięciowych w celu detekcji nieprawidłowości procesu spawania.

\section{Analiza falkowa}

Transformacja Falkowa (analiza Falkowa) dzięki możliwości analizy zmiany częstotliwości sygnału w funkcji czasu należy do zaawansowanych narzędzi przetwarzania i analizy sygnałów a w szczególności sygnałów niestacjonarnych i przejściowych [1][6]. Transformata falkowa jest pozbawiona jest niedoskonałości jaką oferuje powszechnie znana i stosowana transformata Fouriera [4] a mianowicie nie powoduje utraty informacji o czasie, lecz umożliwia jednoczesne przedstawienie czasowych oraz częstotliwościowych zależności między składowanymi analizowanych sygnałów oraz prowadzi do aproksymacji sygnałów przez wyodrębnienie ich charakterystycznych elementów strukturalnych [1].

Transformata falkowa jest przekształceniem podobnym do transformaty Fouriera pod tym względem, iż oba należą do przekształceń całkowych. W odróżnieniu od transformacji Fouriera, gdzie jako jądro wykorzystuje się funkcje sinusoidalne, w przypadku transformaty falkowej jądrem jest falka. Falka jest charakterystyczną funkcją posiadającą zerową wartość średnią, przyjmującą wartości zerowe poza pewnym skończonym przedziałem i posiadającą skończoną moc sygnału. Falki umożliwiają przedstawienie z określoną dokładnością dowolnej funkcji ciągłej poprzez odpowiedni dobór skali (skalowanie) i przesunięcia (przesuwanie).

Dr hab. inż. Marek Fidali - Instytut Podstaw Konstrukcji Maszyn, Politechnika Śląska.

Autor korespondencyjny/Corresponding author: marek.fidali@polsl.pl 

[1]:

Falkowe równanie aproksymujące funkcję f(t) ma postać

$$
f(t)=\sum_{k} \sum_{j} c_{j, k} \psi_{j, k}(t)
$$

gdzie:

$\psi_{j, k}(t)$ - falka o skali j i przesunięciu k w stosunku do falki podstawowej

$c_{j, k}$ - współczynniki falkowe wyznaczane $\mathrm{w}$ procesie aproksymacji.

Pod pojęciem skalowania falki należy rozumieć jej rozciąganie lub ściskanie. Przesunięcie falki to opóźnienie lub przyspieszenie jej początku. Istotę przekształcenia falkowego polegającego generowaniu składowych falek o różnych skalach i przesunięciach przedstawiono na rysunku 1.

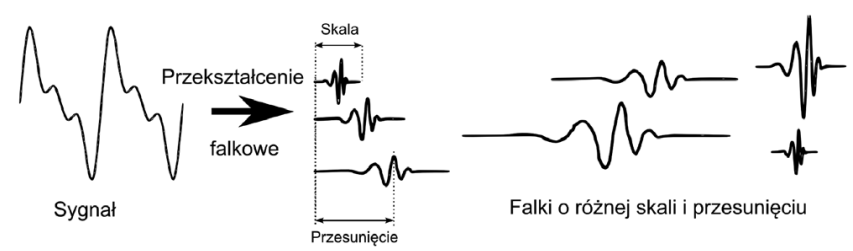

Rys. 1. Przykładowy sygnał i składowe falki o różnych położeniach i skalach [5]

Fig. 1. An example of the signal and wavelet components for different positions and scales [5]

Istnieje związek między skalą falki, a częstotliwością. Niska skala, to ściśnięta falka, szybko zmieniające się współczynniki szczegółowości i wysoka częstotliwość. Wysoka skala natomiast to rozciągnięta falka, wolno zmieniające się cechy sygnału i niska częstotliwość [5].

Wynikiem ciągłej transformaty falkowej jest wykres warstwicowy przedstawiający wartości współczynników falkowych w funkcji czasu i skali (częstotliwości). Wykres ten nazywa się skalogramem. Ciągła transformata falkowa wymaga dużych nakładów obliczeniowych, stąd w praktyce stosowana jest jej dyskretna odmiana, w której współczynniki skali i przesunięcia są liczbami opartymi na potędze liczby dwa. Skuteczny sposób implementacji dyskretej transformaty falkowej bazuje na teorii analizy wielorozdzielczej i algorytmie Malata w którym wykorzystuje się parę filtrów dolno- i górnoprzepustowych (tzw. dwukanałowy koder podpasmowy) (Rys. 2) [5]. Dzięki takiemu podejściu dowolny sygnał można poddać dekompozycji na składową niskoczęstotliwościową przedstawiającą ogólny przebieg sygnału (aproksymację) i składową wysokoczęstotliwościową reprezentującą szczegółowe cechy sygnału (szczegóły) (rys. 2). W odniesieniu do analizy falkowej aproksymacje to elementy sygnału o wysokiej skali i niskiej częstotliwości, a szczegóły to elementy o niskiej skali i wysokiej częstotliwości. Proces dekompozycji jest iteracyjny, więc jeden sygnał może być rozbity na wiele mniejszych elementów.

W zależności od charakteru sygnału poddawanemu przekształceniu falkowemu stosuje się odpowiednio dobraną
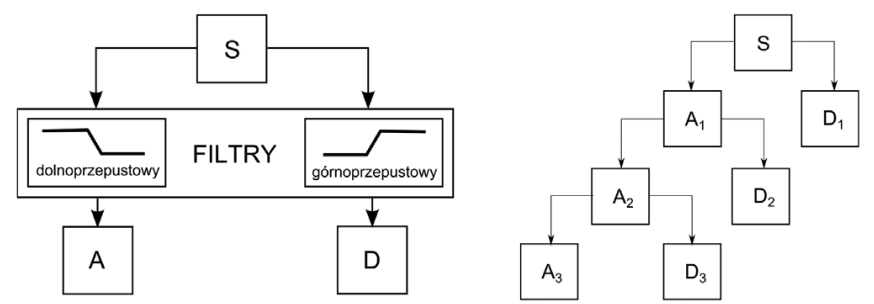

Rys. 2. Istota dekompozycji sygnału na aproksymacje (A) i szczegóły (D) [5]

Fig. 2. The essence of signal decomposition on approximations (A) and details (D) [5] funkcję bazową (falkę). Istnieją różne odmiany i rodziny falek. Dzieli się je na [1]:

- Falki zgrubne (np. Gaussa (Gaus), Morleta (Morl), Kapelusz Meksykański (Mexh))

- Falki regularne (np. Daubechies (dbN), symlety (symN), coiflety (coifN))

- Falki biortogonalne z nośnikiem zwartym w tym falki na podstawie B-splinów (biorNr.Nd, rbioNr.Nd)

- Falki zespolone (np. Gaussa (cgauN), Morleta (cmoFbFc), Shannona (shanFb-Fc)

Na rysunku 3 przedstawiono przykładowe falki z rodziny falek Daubechies stosowane w trakcie badań.

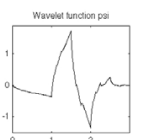

$\mathrm{db} 2$

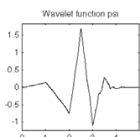

$\mathrm{db} 3$

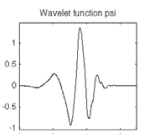

$\mathrm{db} 4$

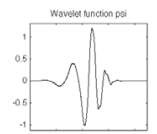

$\mathrm{db5}$

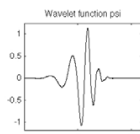

db6
Rys. 3. Przykład funkcji bazowych (falek) z rodziny Daubechies [5] Fig. 3. An example of the wavelets from Daubechies family [5]

\section{Analizaowane sygnały}

Dla potrzeb badań opisanych w artykule wykorzystano rzeczywiste sygnały napięcia zarejestrowane w trakcie spawania odpowiednio przygotowanych próbek wykonanych z prostokątnych blach ze stali S235JR (EN 10027-1) o rozmiarach $300 \times 150 \times 5 \mathrm{~mm}$. Do spawania wykorzystano zmechanizowane stanowisko do prostoliniowego spawania metodą MIG/MAG (Rys. 4). Jako materiał dodatkowy stosowano drut elektrodowy lity o średnicy $1,2 \mathrm{~mm}$. Osłonę gazową stanowiła mieszanka M21 (82\% Ar+18\% CO2). Nominalne parametry spawania zaprezentowano w tablicy I.

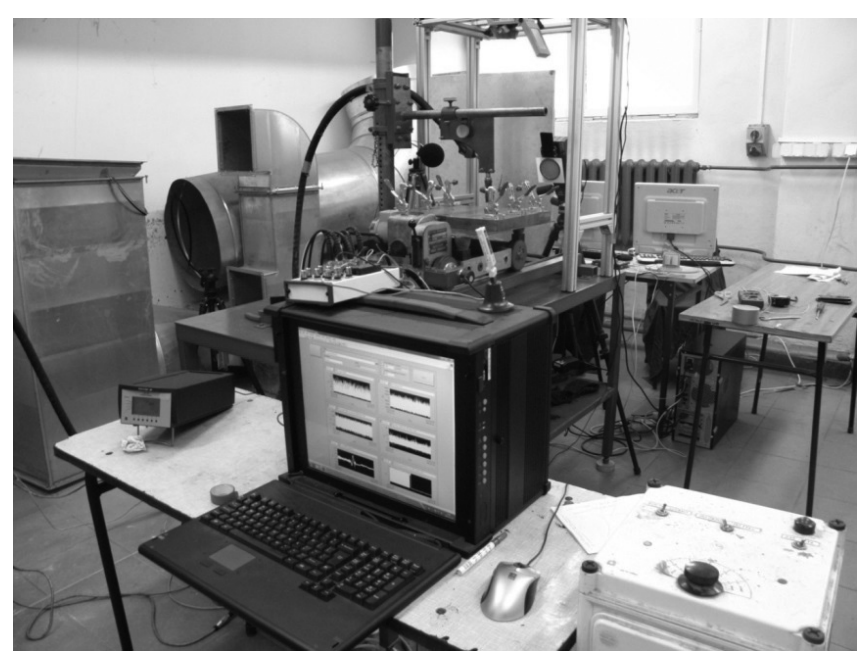

Rys. 4. Widok stanowiska badawczego

Fig. 4. View of the test bench

Na stanowisku badawczym przeprowadzono szereg eksperymentów w trakcie, których symulowano różne nieprawidłowości procesu spawania wpływając tym samym na cechy jakościowe złącza spawanego. Symulowano takie stany procesu spawania jak:

S1 - spawanie w trakcie, którego nastąpił zanik przepływu gazu osłonowego.

S2 - spawanie blach z nieprawidłowym przygotowaniem krawędzi od strony grani (otwory).

S3 - spawanie blach z zabrudzeniami olejowymi na łączonych powierzchniach

S4 - spawanie podczas, którego następowały zmiany wartości prądu 
S5 - spawanie w trakcie którego dokonywano zmian napięcia spawania

S6 - spawanie blach o nierównoległych (rozszerzających się) krawędziach

S7 - spawanie podczas którego nastąpiła destabilizacja prędkości spawania

Eksperymenty przeprowadzono $w$ ramach projektu badawczego nr N504 281937 pt. Metodologia diagnozowania procesu spawania z wykorzystaniem fuzji obrazów realizowanego w Instytucie Podstaw Konstrukcji Maszyn przy współpracy z pracownikami Katedry Spawalnictwa, Politechniki Śląskiej.

Na rysunku 5 przedstawiono widok połączenia spawanego od strony lica i grani uzyskanego podczas spawania w trakcie którego wystąpił dwukrotny zanik przepływu gazu osłonowego.

Tablica I. Nominalne parametry spawania łukowego metodą MAG Table I. Nominal parameters of GMA arc welding

\begin{tabular}{|l|c|}
\hline Prąd Spawania [A] & 240 \\
\hline Napięcie spawania [V] & 25 \\
\hline Prędkość spawania [cm/min] & 32 \\
\hline Prędkość podawania drutu [m/min] & 7,4 \\
\hline Natężenie przepływu gazu osłonowego [I/min] & 15 \\
\hline Wystający odcinek elektrody [mm] & 15 \\
\hline
\end{tabular}
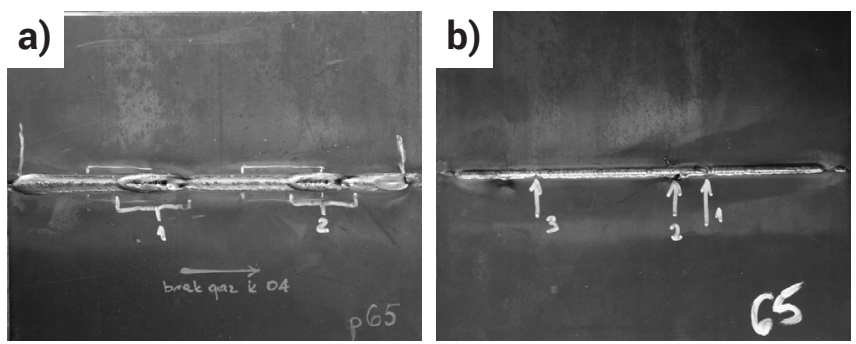

Rys. 5. Widok złącza spawanego od strony lica a) i grani b) uzyskanego podczas spawania z chwilowym zanikiem osłony gazowej Fig. 5. View of the welded joint on the face (a) and root (b) side obtained during welding with the momentary loss of shielding gas flow

\section{Wyniki badań}

Analiza sygnałów napięcia spawania z zastosowaniem transformaty falkowej wymagała przeprowadzenia badań wstępnych polegających na wyborze rodzaju falki i określeniu poziomów dekompozycji falkowej, na których sygnały aproksymacji i szczegółów pozwolą identyfikować nieprawidłowości w procesie spawania.

Dobór rodzaju falki przeprowadzono w sposób eksperymentalny poddając analizie falkowej z różnymi typami falek fragmenty sygnałów dla prawidłowego i zdestabilizowanego procesu spawania. Wyniki w postaci skalogramów porównywano ze sobą w sposób wizualny poszukując jak najbardziej wyraźnych symptomów niestabilności procesowych. Przy wyborze falki posługiwano się również zaleceniami literaturowymi, które mówią, że do oceny sygnałów impulsowych dobrze nadają się m.in. falki Haara i Daubechies [6]. Ostatecznie zdecydowano się na stosowanie falki Daubechies typu db4. Na rysunku 6 przedstawiono przebiegi napięcia spawania dla procesu stabilnego i niestabilnego oraz skalogramy uzyskane w wyniku transformaty falkowej przeprowadzonej z użyciem funkcji bazowych typu Haar i db4. Niestabilności procesu spawania są szczególnie dobrze widoczne na skalogramach otrzymanych przy zastosowaniu falki typu db4.

W ramach badań wstępnych określono również poziomy dekompozycji falkowej, na których sygnały aproksymacji i szczegółów najlepiej odzwierciedlają symulowane niestabilności procesu spawania. Optymalny poziom dekompozycji zależy od rodzaju niestabilności procesowej i dla każdego sygnału dobierano go indywidualnie dla sygnałów aproksymacji i szczegółów. Niestabilności związane ze zmianami napięcia i prądu dobrze ujawniane były przez sygnały aproksymacji wyznaczone na 10 poziomie dekompozycji.

$\mathrm{Na}$ rysunku 7 zaprezentowano przykładowy przebieg sygnału napięcia procesu spawania z widocznymi celowymi zmianami wartości poziomu napięcia oraz sygnał aproksymacji na 10 poziomie dekompozycji. Doskonale widać różnice w odwzorowaniu niestabilności procesu spawania wywołanych zmianami napięcia.

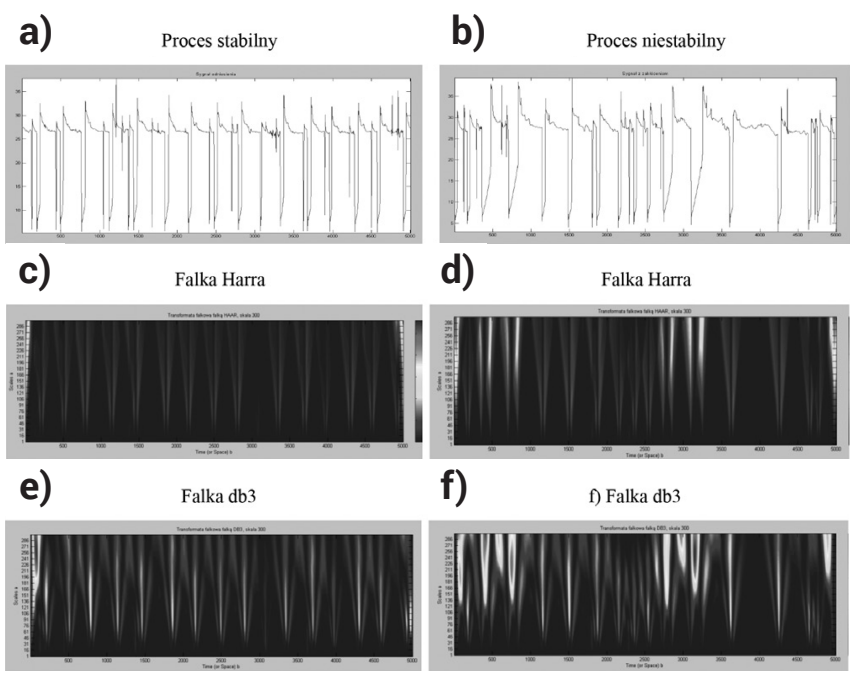

Rys. 6. Przebiegi sygnałów dla stabilnego i niestabilnego procesu spawania i skalogramy uzyskane w wyniku transformaty falkowej z zastosowaniem falek Harra i db3

Fig. 6. Waveforms for stable and unstable welding process and scalegrams obtained from the wavelet transform with use of the Harr and db3 wavelets
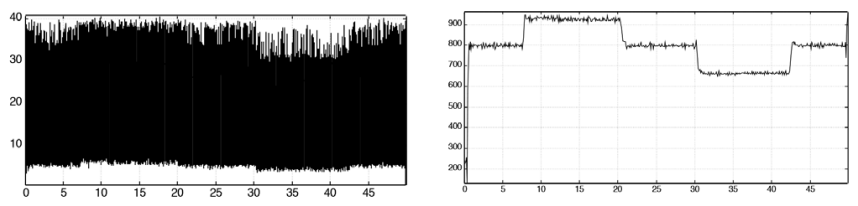

Rys. 7. Przebiegu zmian sygnału napięcia spawania wraz z sygnałem aproksymacji uzyskanym na 10 poziomie dekompozycji falkowej Fig. 7. Changes of welding voltage signal and its approximation obtained on 10 level of wavelet decomposition

$\mathrm{Na}$ podstawie sygnału aproksymacji wyznaczonego na 12 poziomie dekompozycji możliwe było również zidentyfikowanie trudnego $\mathrm{w}$ detekcji na podstawie sygnałów procesowych przypadku zmiany odstępu między spawanymi blachami (rys. 8). Na sygnale aproksymacji dostrzegalny jest wyraźny trend liniowy korespondujący ze zmieniającą się odległością między spawanymi blachami.

Sygnały szczegółów dobrze uwidaczniały niektóre z symulowanych niestabilności procesu spawania na 7 i 8 poziomie dekompozycji falkowej. Rysunek 9 przedstawia przebieg sygnału napięcia spawania podczas symulowanego dwukrotnego zaniku gazu osłonowego oraz odpowiadający mu sygnał szczegółów wyznaczony na 7 poziomie dekompozycji falkowej.

Nie wszystkie nieprawidłowości procesu spawania można było jednoznacznie wykryć bezpośrednio z sygnałów aproksymacji i szczegółów. W niektórych przypadkach, 
konieczne było przeprowadzenie dodatkowej analizy polegającej na wyznaczaniu wybranych cech sygnałów takich jak np. wartość skuteczna (RMS), wariancja (Var) czy rozstęp ćwiartkowy (IQR). Cechy sygnałów wyznaczane były dla odcinków sygnału o określonej długości, na które dzielono sygnały aproksymacji i szczegółów. Postępowanie takie pozwoliło na uzyskanie sygnałów diagnostycznych umożliwiających detekcję obszarów występowania niestabilności procesowych. Na rysunku 10 przedstawiono przykładowy przebieg sygnałów diagnostycznych wyznaczonych z sygnału szczegółów na 7 poziomie dekompozycji falkowej. Sygnał dotyczy przypadku spawania, w trakcie którego nastąpiła destabilizacja prędkości spawania. Przypadek ten był trudny do zidentyfikowania bezpośrednio na podstawie przebiegu sygnału napięcia spawania i sygnału szczegółów. Dzięki dodatkowej analizie możliwe było wykrycie obszaru niestabilności, który najlepiej widoczny jest na przebiegu wartości rozstępu ćwiartkowego i wartości wariancji.

Nie wszystkie nieprawidłowości procesu spawania można
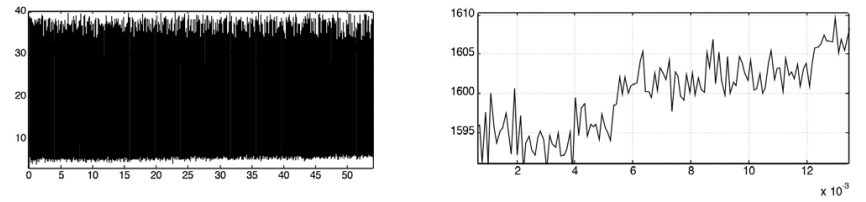

Rys. 8. Przebieg sygnału napięcia spawania i jego aproksymacja na 12 poziomie dekompozycji falkowej dla przypadku spawania blach o zmieniającym się odstępie

Fig. 8. Waveform of welding voltage and its approximation on the 12th level of wavelet decomposition for welding conditions S6
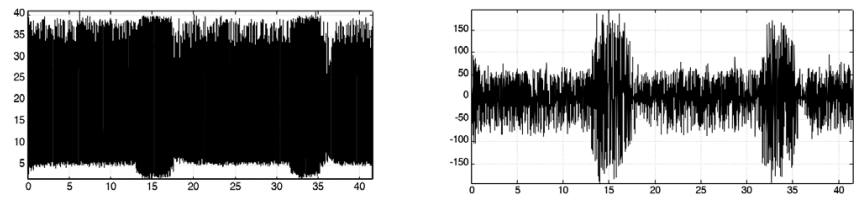

Rys. 9. Przebieg sygnału napięcia spawania i sygnał szczegółów na 7 poziomie dekompozycji falkowej dla procesu spawania w trakcie którego nastąpiły zaniki w przepływie gazu osłonowego

Fig. 9. Waveform of welding voltage and its details on the 7th level of wavelet decomposition for the welding process during which there were lapses in the flow of the shielding gas było jednoznacznie wykryć bezpośrednio z sygnałów aproksymacji i szczegółów. W niektórych przypadkach, konieczne było przeprowadzenie dodatkowej analizy polegającej na wyznaczaniu wybranych cech sygnałów takich jak np. wartość skuteczna (RMS), wariancja (Var) czy rozstęp ćwiartkowy (IQR). Cechy sygnałów wyznaczane były dla odcinków sygnału o określonej długości, na które dzielono sygnały aproksymacji i szczegółów. Postępowanie takie pozwoliło na uzyskanie sygnałów diagnostycznych umożliwiających detekcję obszarów występowania niestabilności procesowych. Na rysunku 10 przedstawiono przykładowy przebieg sygnałów diagnostycznych wyznaczonych z sygnału szczegółów na 7 poziomie dekompozycji falkowej. Sygnał dotyczy przypadku spawania, w trakcie którego nastąpiła destabilizacja prędkości spawania. Przypadek ten był trudny do zidentyfikowania bezpośrednio na podstawie przebiegu sygnału napięcia spawania i sygnału szczegółów. Dzięki dodatkowej analizie możliwe było wykrycie obszaru niestabilności, który najlepiej widoczny jest na przebiegu wartości rozstępu ćwiartkowego i wartości wariancji.
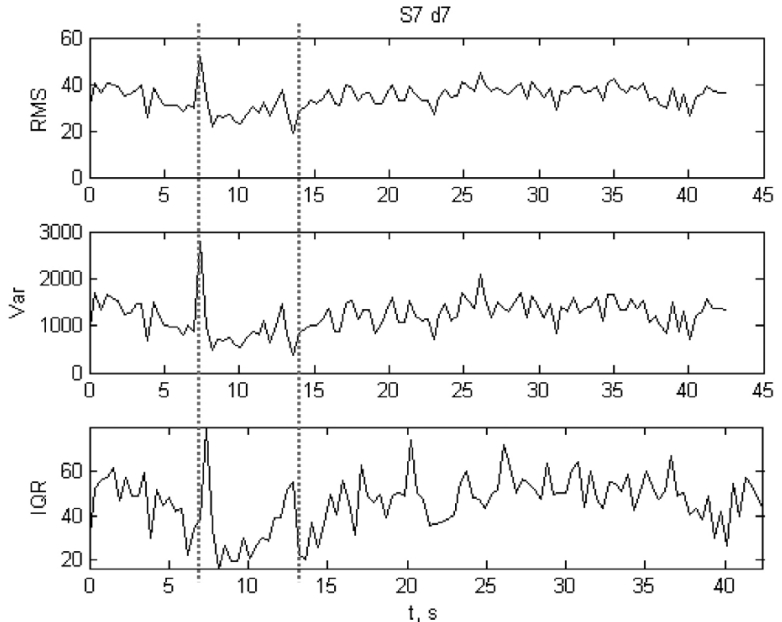

Rys. 10. Przykład sygnałów diagnostycznych otrzymanych na podstawie sygnału szczegółów na 7 poziomie dekompozycji dla procesu spawania w trakcie którego nastąpiła destabilizacja prędkości spawania

Fig. 10. Example of diagnostic signals calculated on the basis of the details on 7th wavelet decomposition level for the welding process during which destabilisation of the welding speed occurred

\section{Podsumowanie}

Transformata falkowa jest zaawansowanym narzędziem przetwarzania sygnałów, które również doskonale nadaje się do separacji informacji diagnostycznych z sygnałów napięcia spawania. Jak pokazują wyniki badań dzięki zastosowaniu dekompozycji falkowej możliwa jest detekcja szeregu nieprawidłowości procesu spawania. Niestety nie wszystkie niestabilności procesu spawania odzwierciedlane są w sygnale napięciowym. Należy się spodziewać, że inne sygnały procesowe (np. sygnał akustyczny) poddane przekształceniu falkowemu pozwolą ujawnić trudne do wykrycia niestabilności procesu spawania, co będzie przedmiotem dalszych badań autora.

\section{Literatura}

[1] Białasiewicz J. T., Falki i aproksymacje, WNT 2004

[2] Jiluan P., Arc Welding Control, Woodhead Publishing Ltd. (2003).

[3] Luksa K.: Monitorowanie procesów spawania. Biuletyn Instytutu Spawalnictwa, nr 5/1999.

[4] Lyons R.G.: Wprowadzenie do cyfrowego przetwarzania sygnałów, Wydawnictwo Komunikacji i Łączności 2006
[5] Misiti M., Misiti Y., Oppenheim G., Poggi J-M., Wavelet Toolbox for use with Matlab. The MathWorks, Inc. 1997.

[6] Timofiejczuk A.: Metody analizy sygnałów niestacjonarnych. Gliwice 2004. 